\title{
Women as an Image in War Propaganda Posters
}

\author{
Eren Evin Kılıçkaya Boğ *
}

Kütahya Dumlupinar University, Turkey

\begin{abstract}
The images of women are prevalent in societies globally from advertising to graphic design products with implications about the social roles women embedded in the imagery. In these examples, the images of women frequently stress heterosexual ideals as the forefront of femininity, often with the roles of mother and a housewife. Especially during the World War I and II, in the posters designed for war propaganda, women took on new roles. In the war propaganda posters, the images of women were undertaken different roles with the support of semi-masculine, brave and strong characteristics. The women were encouraged that they have a capability to do every hard work and they were convinced that they could take over the men's job often very willingly. In this essay, especially the American war propaganda posters examined deeply in terms of societal and social within the images of women. This essay is important not only it forms a basis content of social messages, but also it provides the roots of extensive consciousness of feminism, the economic power of woman and the equality of women and men in the world.
\end{abstract}

Keywords: War Posters, Propaganda, Poster Design, The image of woman

\section{Introduction}

Society has a great power of giving social roles to the genders from the birth or early childhood. As B. Longhurst said that (2008, p.218), gender is often regarded as a cultural overlay to the anatomically founded difference between the sexes. Sex refers to biological differences between males and females while gender refers to the culturally specific ways of thinking, acting and feeling. According to this idea, the roles of men or women are shaped to the gender profiles in mass communication. Femininity and masculinity are the gender terms, referring to the ways of thinking, acting and feeling considered appropriate roles for females or males.

In most of the societies it is inevitable that there will be a range of femininities and masculinities to be found. These notions create the culturally dominant gender codes that movies, advertising and so on both draw upon and help to construct. "In contemporary western culture, femininity seems to be very much more representational and self-presentational matter than the masculinity. It is said that men act, while women appear-women trade on their 'looks' men on their "presence"' (Longhurst, 2008, et al. p.218). Women have a more powerful role on selling or buying something with the rising of their economical power, which is given to the women by replacing the men's job.

"Clearly men do not passively live out the masculine myth imposed by the stories and images of the dominant culture. But neither can they live completely outside the myth, since it pervades the culture. Its coercive power is active everywhere-not just on screens, hoardings and paper, but inside our own heads" (Storey, 2006, p. 123)

Contemporary femininity is constructed; according to some paradoxes; for example the looks of the human body are very much more important for the women than the men: attractiveness matters much more to how women are regarded and regard themselves. So many women work hard to stabilize the beauty of theirselves by means of cosmetics, diet regimes, plastic surgery, injections, liposuction and the like. Similarly, the men are supposed to be stronger, healthier, powerful images as they are coded. The goal of this paper is to take closer look at to understand how an image used in a poster can change the perception of public point of view in the name of society roles. 


\title{
What is a Poster?
}

According to Harold Hutchinson's definition, at the beginning of his book The Poster, An Illustrated History from 1860 (London, 1968):

\begin{abstract}
"A poster is essentially a large announcement, usually with a pictorial element, usually printed on paper and usually displayed on a Wall or billboard to the general public. Its purpose is to draw attention to whatever an advertiser is trying to promote and to impress some message on the passer-by. The visual or pictorial element provides the initial attraction-and it must be striking enough to catch the eye of the passer-by and to overcome the counter-attractions of the other posters, and it usually needs a supplementary verbal message, which follows up and amplifies the pictorial theme. The large size of most posters enables this verbal message to be read clearly at a distance" (Sontag, 1999, p.197).
\end{abstract}

A poster's first job is to promote something to the public audience. According to Susan Sontag (1999, p.198), the earliest famous posters all had a specific function: to encourage a growing proportion of the population to spend money on soft consumer goods, entertainment, and the arts. The main point of the poster is its message. Usually there is a slogan that supports the advertisement, the announcement in most of the posters.

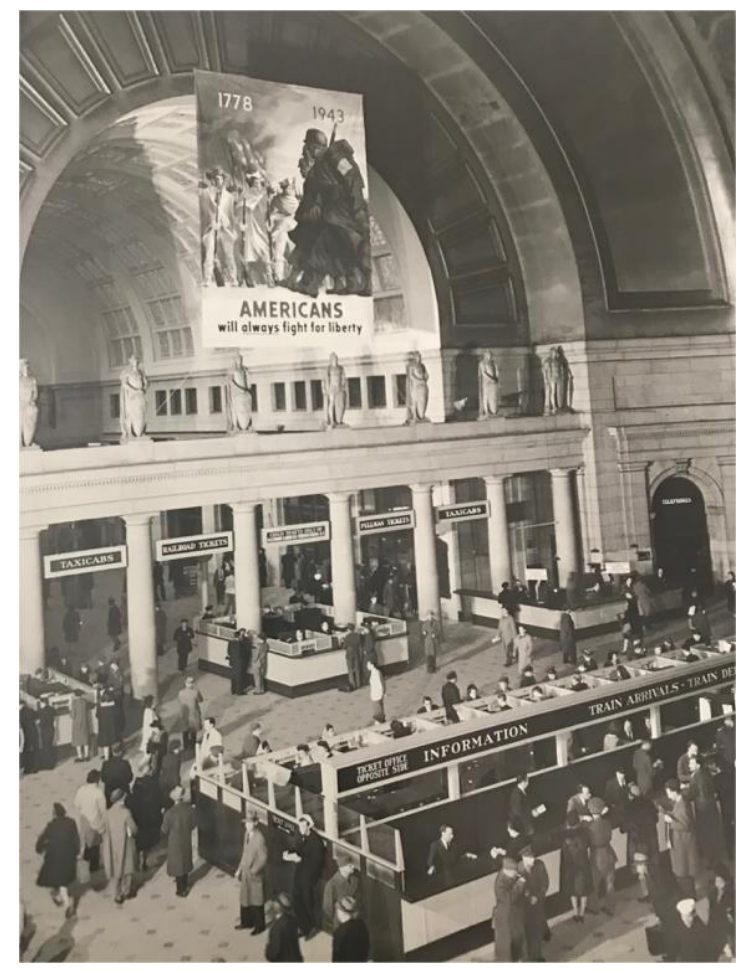

Figure 1- Poster from the old times.

\section{Propaganda Posters}

According to Kathleen M. Ryan (2012, p. 248), propaganda is 'the deliberate, systematic attempt to shape perceptions, manipulate cognitions and direct behavior to achieve a response that furthers the desired intent of the propagandist. Propaganda is a form of communication to distribute information. The information is designed to make people feel a certain way or to believe a certain thing. The word 'propaganda' comes from Latin. At first, it meant 'ideas to be spread around'. But in the First World War, it came to mean 'political ideas that are supposed to be misleading'. During the Second World War, propaganda developed with the advance of mass media. 
"By the mid-twentieth century, the rhetoric of propaganda had shifted, from the notion of propaganda as a value-neutral persuasive interaction to an idea that propagandistic persuasion was somehow forced upon a powerless audience. Propaganda, fraught with negative associations, was replaced by more neutral terms such as 'information', 'communication' or 'persuasion' Scholars considered the influence and ethics of social psychology, dissected the role of mass persuasion and offered a model to determine if one had been influenced by propaganda" (Ryan, 2012, p. 249).

In western culture, the relationship between propaganda, public information and advertising is intimate and the poster designers used the language of propaganda often in their works.

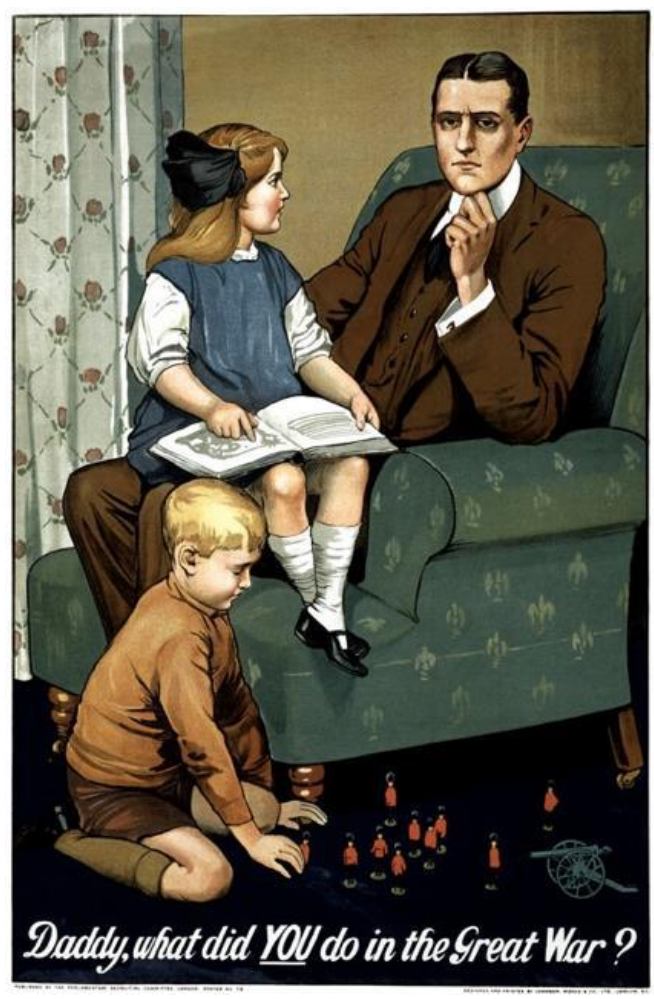

Figure 2- One of the propaganda poster promoting the war.

"The art of the propaganda is not necessarily ennobled or refined by powerlessness, any more than it is inevitably coarsened when backed by power or when serving official goals. What determines whether good political posters are made in a country, more than the talent of the artists and the health of the other visual arts, is the cultural policy of the government or party or movement- whether it recognizes quality, whether it encourages, even demands it. Contrary to the invidious idea many people have about propaganda as such, there is no inherent limit to the aesthetic quality or moral integrity of political posters-no limit, that is, separate from the conventions that affect (and perhaps limit) all poster-making, that done for commercial advertising purposes as much as that done for the purposes of political indoctrination" (Sontag, 1999, p.203).

\section{War Posters}

Posters were a major part of the overall propaganda effort during World War I and II, coordinated by some national services. The designs varied from small tabletop displays to roadside billboards. Posters played a major role in the minds of the American citizens that helped to sustain the war effort throughout the battle. The Examples are much the posters of American posters, because the idea of the posters for the propaganda comes 
from the American tradition and the poster art was the key point of American advertising. So it is not coincidence that there were more examples from American culture.

\section{Reading First World War Posters}

"Collections of World War I posters provide a window onto a world that has largely vanished, but it has left behind so many iconic images that when we see them, we conjure up an entire set of representations of war. It is these that frame what Samuel Hynes has called our "war in the head," our mental furniture on which perch our images of war. These images are not memories - we were not there-but they are representations of the memories of others who were there. Many of those who designed posters brought to the task personal experiences and recollections. Many of those who viewed them during the war certainly linked them to memories of a personal kind" (Pearl, 2009, p.52).

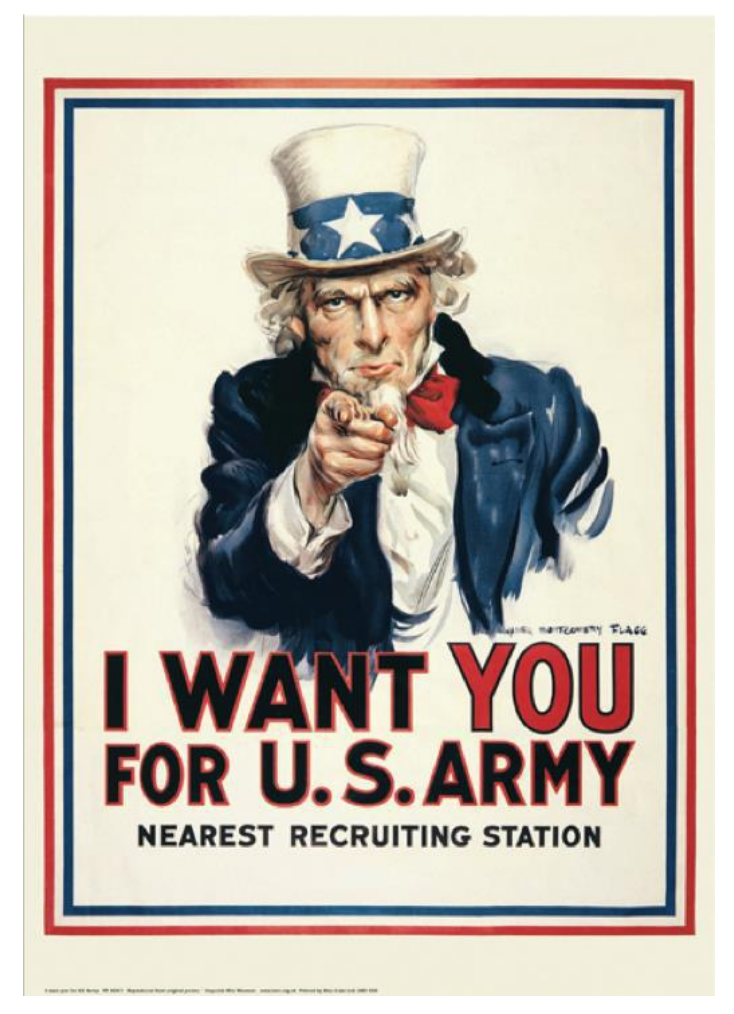

Figure 3- I want you for the U.S. Army Poster

Above is the famous war propaganda poster of American culture. Uncle Sam was pointed the viewer and persuaded to join the army. This iconic poster gains a symbolic meaning of American popular culture and affects other ideas, which are related to want somebody to do something.

\section{Reading Second World War Posters}

The posters designed during the Second World War, the graphical point of view also changed according the usage of texts and images. The tendency of using Bold Typography can be seen clearly in most of these examples. Also the role of women had changed in the Second World War posters, the women were not the person only that says 'Good by' to their husbands and men. They had gained a powerful images and persuading the braveness and masculinity. 


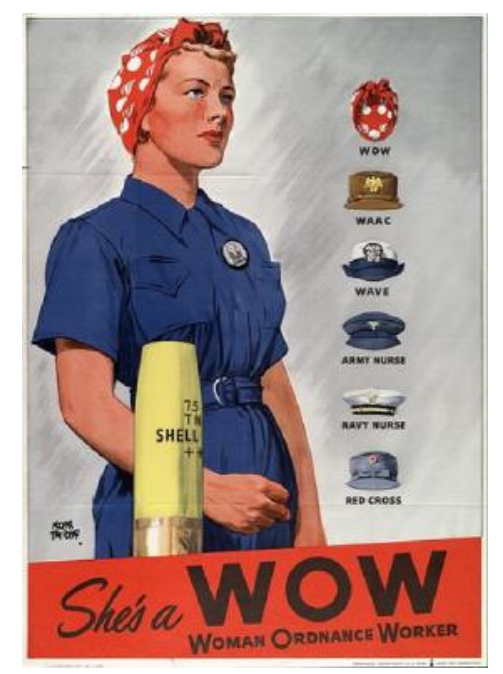

Figure 4- She's a WOW poster

\section{Women in War Propaganda Posters}

Collections of World War posters provide a range window onto a world that has largely vanished, but it has left behind so many iconic images of women that when we see them, we recognize an entire set of representations of war and the role of women in war.

In most of the posters the women image used as a persuasive role during First and Second World Wars. You can easily recognize the role of women that used in posters. The usage of handwritten typography and the role of women gave clues about the period of the posters. In figure 5, the $\mathrm{V}$ shape in the background represents the $\mathrm{V}$ for Victory.

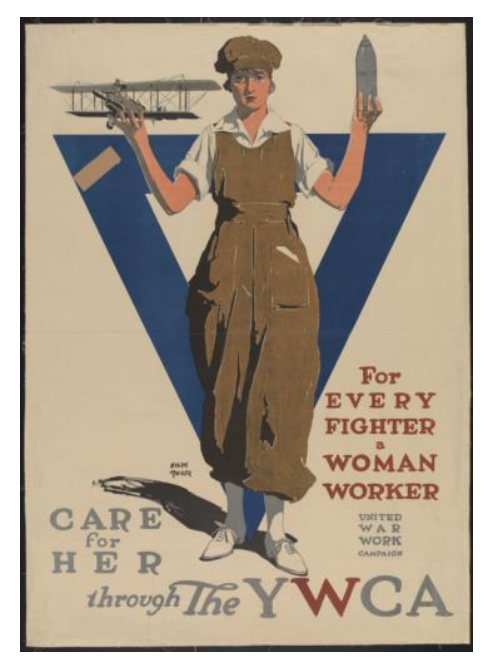

Figure 5- For Every Fighter a Woman Worker.

White (2006, p.156) said that the power to oppress women, to restrict their sense of who they are and who they could be, is laid at the feet of patriarchy and capital, and given a recognizable face in the media. Media texts seduced women to comply with their subservient positions in the world. So the image of woman has a great power in poster art. In Figure 6, the woman was used as a representational image of the French revolution woman figure in the painting of Eugene Delacroix. She holds a flag and dresses also drapery look like the French version. Above of all the soldiers (men), the center image is the key point for victory. 


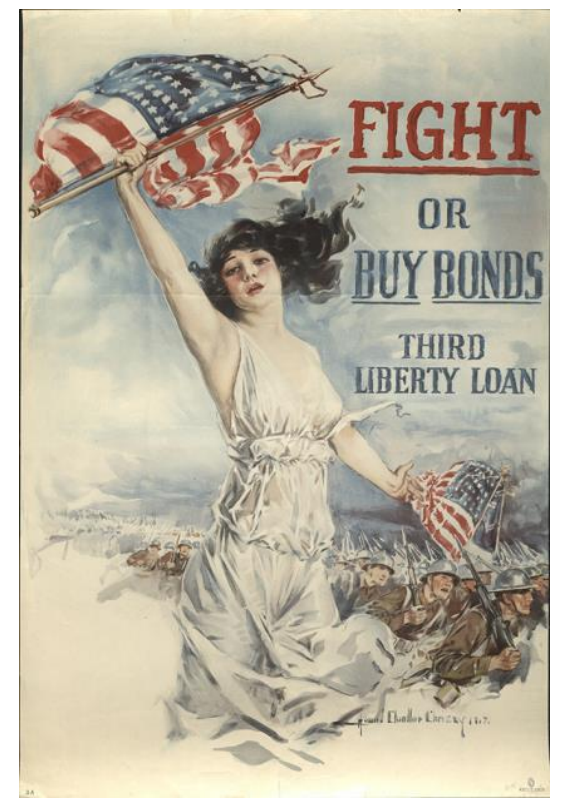

Figure 6- Fight or Buy Bonds.

In figure 7 and 8 , also the images of women are working for the victory. Figure 7 shows the women taking row with the dresses like men's dressing and it supports the masculinity and the power. The message is powered by showing the victory is not deserved without any effort and pain.

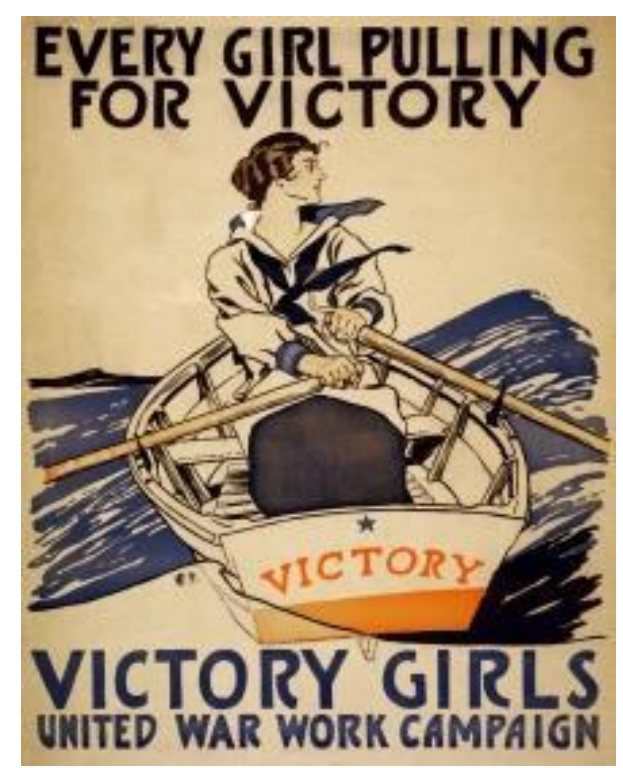

Figure 7- Victory Girls, every girl pulling for victory.

The woman figure holding American flag that is flying proudly is again dressed like a man and the other workingwomen also look like masculine. The message is given again with the idea of woman has to work if she deserves better war conditions. 


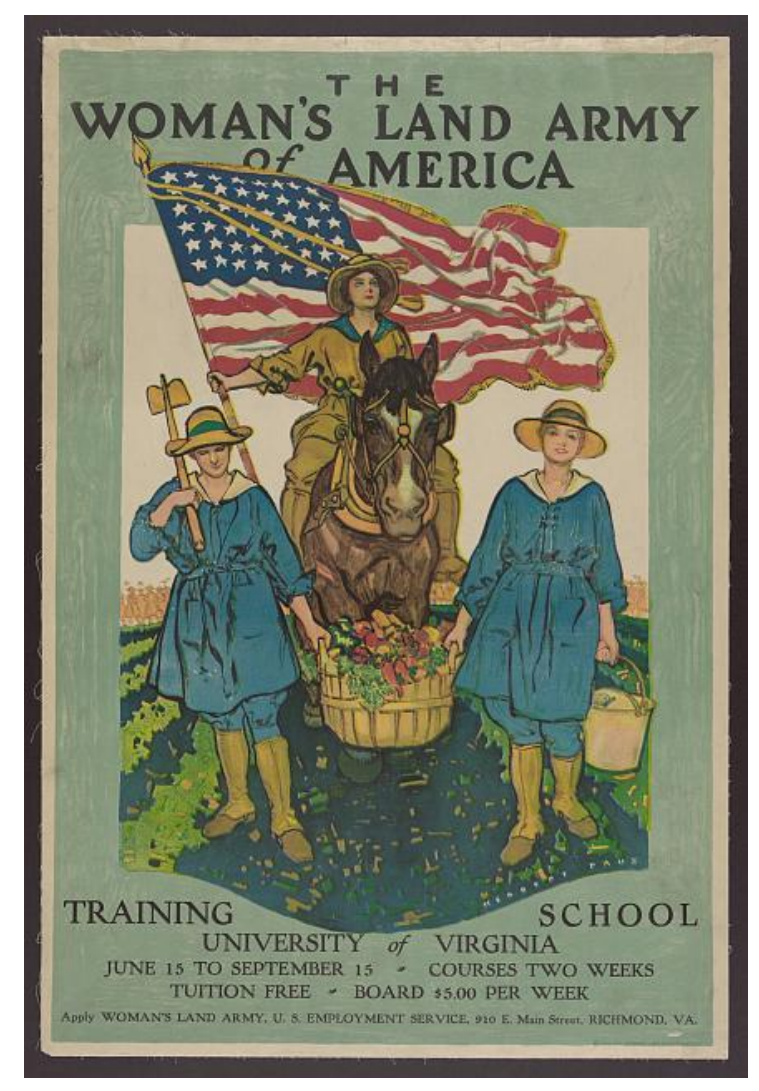

Figure 8- The Woman's Land Army of America.

\section{What Did Women Do in the War Time?}

According to Alison S. Fell (2018, p.2), for those women, the years 1914-18 sometimes meant a new experience of work, or a case of carrying out their pre-war jobs in contexts that had been transformed by war. For the thousands of women who had worked before the war it was often a question of changing one form of waged labor for another.

\footnotetext{
"To some extent, the legacies of the First World War on women's lives differed according to whether they had been engaged in what they considered to be work or service. For middle-and upper-class women, the war did not tend to lead to careers, but to a domestic life of marriage and motherhood. Yet the widened social networks, new opportunities and greater independence the war had often brought with it undoubtedly had an impact-which is difficult to measure-on these women's understanding of their rights, roles and relationship to the state" (Fell, 2018, p.6).
}

One of the workingwoman has a special place in posters history. In 1942, the seventeen-year-old Geraldine Hoff Doyle was the inspiration of workingwoman during wartime. In figure 9, she was seen working on a riveter machine with her red dotted scarf. She has both masculine and feminine look. Poster artist J. Howard Miller, who was given responsibility to make a poster of reassurance to the public, turned her an iconic symbol of workingwoman of wartime. 


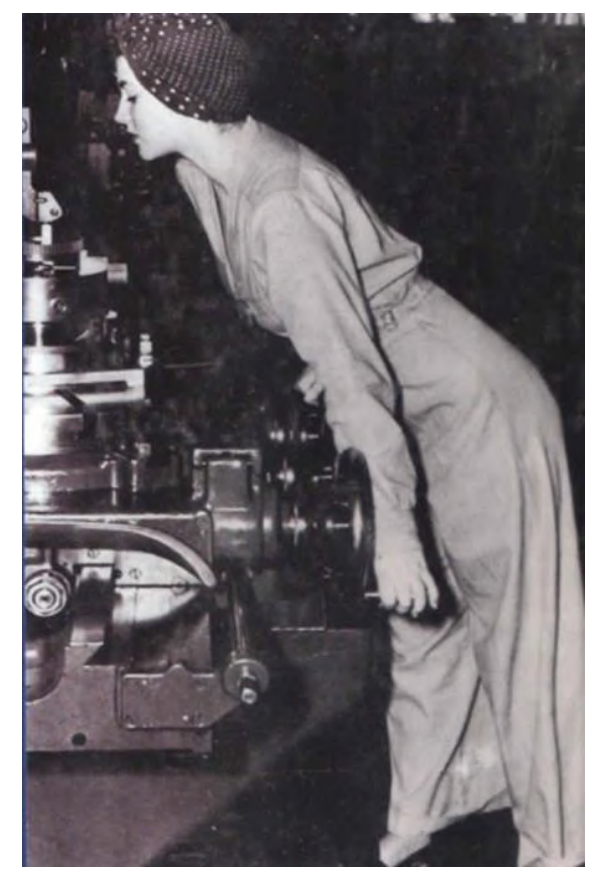

Figure 9- Working woman named Geraldine Hoff Doyle

"Rosie the Riveter was the star of a campaign aimed at recruiting female workers for defense industries during World War II, and she became perhaps the most iconic image of workingwomen. American women entered the workforce in unprecedented numbers during the war, as widespread male enlistment left gaping holes in the industrial labor force. Between 1940 and 1945, the female percentage of the U.S. workforce increased from 27 percent to nearly 37 percent, and by 1945 nearly one out of every four married women worked outside the home. While women during World War II worked in a variety of positions previously closed to them, the aviation industry saw the greatest increase in female workers" (https://www.history.com/topics/world-war-ii/rosie-the-riveter).

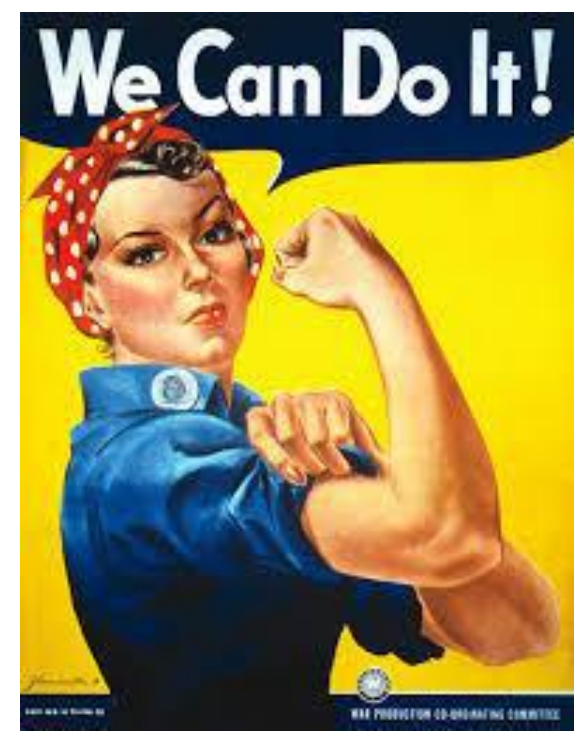

Figure 10- Famous "We can Do It" Poster, J. Howard Miller 
This poster became the major element of female power and the feminism movement after the Second World War. It was used many places to force the women's heritage and role in society. Her red dotted scarf also gains a symbolic meaning of woman power, braveness and changing situation of gendered roles.

\section{Conclusion}

War posters had a deep effect on society, especially that they were the wide range of communication method. The images of women were seen to reinforce the women contribution to the economical and societal life. Gender roles became to change after the Second World War, that woman was not the only person staying at home and looking the children. For many women, the war effort offered opportunities for volunteer service to the nation and for the others; the war provided new, employment options instead of men. Especially in American society the women workers are deeply emphasized from the persuasive roots of wartime.

\section{References}

Christopher, J. (2014). British Posters of the First World War. Gloucester, England: Amberley Publishing.

Fell, A. S. (2018) Woman and the First World War, England: Adam Matthew Digital.

Longhurst, B., Smith, G., Bagnall, G., Crawford, G., \& Ogborn, M. (2008). Introducing cultural studies, England: Pearson Longman.

Pearl, J. (2008). Picture this-World War I posters and visual culture, Lincoln: University of Nebraska Press.

Ryan, K.M. (2012). Don't miss your great opportunity: patriotism and propaganda in Second World War recruitment. Visual Studies, 27(3), 248-261.

Sontag, S. (1999). Posters: advertisement, art, political artifact, commodity. In M. Bierut, J. Helfand, S. Heller \& R. Poynor (Ed.), Looking Closer 3, Classic Writings on Graphic Design (pp. 196-218). New York: Allworth Press.

Storey, J. (2004). Cultural theory and popular culture an introduction. USA: The University of Georgia Press. White, M. \& J. Schwoch, (2006). Questions of method in cultural studies, New Jersey: Blackwell Publishing. https://www.history.com/topics/world-war-ii/rosie-the-riveter 